Running head: AGING AND ASSOCIATIVE MEMORY

\title{
Age-related Decline in Associative Memory: Understanding the Roles of Controlled and Automatic Processes
}

\author{
Jimmy Y. Zhong
}

School of Psychology, Georgia Institute of Psychology, Atlanta, GA, USA

Address for Correspondence:

Cognitive Neuroscience of Aging Lab

GSU/GT Center for Advanced Brain Imaging

831 Marietta Street NW

Atlanta, GA 30318

Email: jzhong34@gatech.edu

Phone: 1-404-385-0523 (Lab)

1-404-385-8619 (CABI center) 
AGING AND ASSOCIATIVE MEMORY

1

2

3

4

5

6

7

8

\section{INTRODUCTION}

A substantial volume of past research has demonstrated that memory capabilities decline in old age (e.g., see Craik \& Jennings, 1992; Hoyer \& Verhaeghen, 2006; Zacks, Hasher, \& Li, 2000, for reviews). This decline is highly noticeable based on tasks assessing episodic memory, which require remembering information about events at specific times and places (e.g., Craik \& Jennings, 1992;

Naveh-Benjamin \& Old, 2008; Zacks et al., 2000). The exact cognitive mechanism that accounted for this prominent age-related decline in episodic memory has not been well-understood, and the multitude of mechanisms that were proposed have drawn a credible amount of research and discussions (for reviews, see Light, 1991; Salthouse, 1991; Hoyer \& Verhaeghen, 2006).

With an intention to provide a more valid account of this exceptional agerelated deficit, this review focuses on an associative-binding hypothesis that was suggested to form the basis of age-related declines in episodic memories. According to the associative deficit hypothesis (ADH) (Naveh-Benjamin, 2000; see also Bayen, Phelps, \& Spaniol, 2000; Chalfonte \& Johnson, 1996; Naveh-Benjamin, Hussain, Guez, \& Bar-On, 2003), older adults' poorer episodic memory is attributed to the difficulties they experience in formulating relations or links between single units of information, binding them together into a coherent distinctive unit, and retrieving the links between the component features/units whenever necessary. A coherent 


\section{AGING AND ASSOCIATIVE MEMORY}

1 distinct unit is generally regarded to comprise of two units of information, either of

2 which can manifest itself in the form of items (e.g., words, faces, pictures; see

3 Naveh-Benjamin, 2000; Naveh-Benjamin et al., 2003; Naveh-Benjamin, Guez, Kilb,

$4 \quad \&$ Reedy, 2004) or contextual elements/features (e.g., colors, object locations; see

5 Mitchell, Johnson, Raye, Mather, \& D’Esposito, 2000b).

6 The $\mathrm{ADH}$ is supported by numerous experiments showing that older adults are

7 deficient at preserving the links between the two basic components of an episode,

8 despite having relatively intact memory for the separate components. This pattern

9 of results, commonly based on a recognition memory testing paradigm, has been reported for associations between paired words (Castel \& Craik, 2003; Healy, Light,

11 \& Chung, 2005; Light, Patterson, Chung, \& Healy, 2004; Naveh-Benjamin, 2000,

12 Experiment 2), paired faces (Bastin \& Van der Linden, 2005), paired pictures

13 (Naveh-Benjamin et al., 2003), pairings of words and non-words (Naveh-Benjamin,

14 2000, Experiment 1), pairings between words and their fonts (Naveh-Benjamin,

15 1995, Experiment 1; Naveh-Benjamin, 2000, Experiment 3), pairings of names and

16 faces (James, Fogler, \& Tauber, 2008; Naveh-Benjamin et al., 2004; Rendell, Castel,

$17 \&$ Craik, 2005), pairings of pictograms of objects and their locations on a grid

18 (Mitchell et al., 2000b), and pairings of people and activities (Kersten, Earles,

19 Curtayne, \& Lane, 2008). These studies typically present younger and older adults

20 with learning episodes containing two components each (e.g., word and non-word

21 pairs) before testing their memory of the components using an item recognition test

22 and the associations between the items using an associative recognition test. The 


\section{AGING AND ASSOCIATIVE MEMORY}

1 strength of this testing paradigm lies in its ability to provide a direct measure of an

2 individual's level of associative learning without being hindered by potential

3 individual differences in retrieval processes. Notably, it circumvents the problems

4 posed by the cued-recall task (e.g., see Dunlosky \& Hertzog, 1998, 2001), which

5 requires the learning of paired associates followed by the recall of one of its item

6 after being cued by its affiliate. Such problems are encapsulated by not being able to

7 clarify whether the deficit shown by older adults in those tasks is due to a decline in

8 associative memory or reflective of some additional age-related deficits in item

9 retrieval under the presence of cues (see Old \& Naveh-Benjamin, 2008). Hence, in

10

11

12 comparison, the associative recognition paradigm endorsed by the aforementioned studies could be seen as engendering a more precise account of older adults' poorer memory performance - one that is untainted by the extraneous influence of retrieval processes.

These findings generated more discussions of the general cognitive processes or mechanisms underlying the associative memory deficit in older adults. A notable concern of memory performances lies in the distinction between automatic and controlled (i.e., effortful-strategic) processes (Hasher \& Zacks, 1979). Strategiceffortful processes are commonly characterized as conscious, slow-occurring, intentional, and cognitively demanding whereas automatic processes are generally regarded as unconscious, implicit, fast-occurring, and non-effortful (e.g., see Hasher \& Zacks, 1979; Posner \& Snyder, 1975; Schneider \& Shiffrin, 1977). 
AGING AND ASSOCIATIVE MEMORY

1

2

列

In view of the considerable volume of research that has been generated investigating whether older adults' associative deficit is due to the lack of appropriate strategies to bind together two components, by an inability to bind them automatically, or by both, the focus of this review will be on the empirical studies that sought to delineate the roles of these types of processes in engendering the decline of episodic/associative memory in older adults. I will discuss the studies that implicated the involvement of strategic-effortful/controlled processes in the age-related decline in associative memory, brought about by the influences of instructions, attention, strategies, and automatic processes. These comparisons will be followed up by a survey of the neural correlates that were implicated to be underpinning the age-related deficit in associative memory. Based on an overview of the studies, limitations and recommendations for future research will be proposed for a better understanding of the sources of this associative deficit.

\section{THE ROLE OF INSTRUCTIONS ON ASSOCIATIVE LEARNING}

16

A foremost indicator of older adults' deficiency in strategic-effortful processing relates to the meta-analytic finding that the age effect derived from associative memory tasks (with younger adults having higher scores than older adults) is greater under intentional learning instructions - whereby participants were specifically told to prepare for a particular memory task - than under incidental learning instructions that do not provide details of the upcoming task (Old \& 


\section{AGING AND ASSOCIATIVE MEMORY}

1 Naveh-Benjamin, 2008). This suggests that older adults' associative memory deficit

2 is mediated by difficulties in the optimal allocation of cognitive resources or the use

3 of appropriate strategies for encoding associations. In comparison with younger

4 adults, older adults did not seem to be able to take advantage of the strategy

5 provided by intentional instructions to facilitate their associate learning, and

6 consequently was not able to exhibit any noticeable improvement in their

7 association memory performance (see Naveh-Benjamin, 2000; Experiment 2). This

8 inability of older adults to adapt to the use of specific strategies can also be seen

9 from studies that showed them to have applied a smaller proportion of strategies

10 (based on verbal and mental imagery mediators) than younger adults in the correct

11 recall of paired associates (e.g., Smith, Park, Earles, Shaw, \& Whiting, 1998;

12 Dunlosky \& Hertzog, 2001).

The first study that explored the differential effects of incidental and

14 intentional instructions on item and associative memory respectively was performed

15 by Naveh-Benjamin et al. (2000). In their second experiment, they showed younger

16 (mean age of 22) and older adults (mean age of 71.1) word-nonword pairs in a

17 sequential manner, with one pair appearing after another on each trial. In each age

18 group, half of the participants were given incidental instructions to study the words

19 in each pair individually in preparation for the upcoming item recognition test

20 whereas the other half were given intentional instructions to study the paired items

21 in preparation for the upcoming associative recognition test. In the recognition

22 tests, the original items or pairs were intermixed with a proportionate number of 


\section{AGING AND ASSOCIATIVE MEMORY}

1 distracter items. Distractor items from the word and nonword recognition tests were

2 novel items that were not shown during the study phase and distracter items from

3 the word-nonword recognition test referred to different combinations of previously

4 studied pairs that were not observed. To avoid any carryover effects, a word or non-

5 word appeared only once in each of the three recognition tests.

6 The results were computed in terms of a discriminability index-proportion hits

7 minus proportion false alarms-that serves as a normative index for evaluating

8 recognition memory performance. A differential pattern of results emerged for both

9 age groups under the different types of instructions. In the item recognition memory

10 test, there was a main effect of age (in favor of the younger adults) with no

11 significant interaction of age and instructions. In contrast, there was a significant

12 interaction effect between age and instruction in the associative test, with the age

13 group difference being relatively larger (i.e., younger adults achieving higher scores)

14 under intentional learning (see Figure 1.1) ${ }^{1}$. These peculiar findings from the

15 associative test suggest that younger adults benefited more from intentional

16 instructions that explicitly emphasized the conjunctive encoding of item pairs. Older

17 adults, on the other hand, exhibited the same level of associative memory

18 performance irrespective of the type of instructions they were given, and did not

19 appear to have adapted their cognitive processing in a way that adequately

20 addressed the demands of the relational/connective strategy that is intrinsic to the

\footnotetext{
${ }^{1}$ See Appendix for figures.
} 


\section{AGING AND ASSOCIATIVE MEMORY}

1 intentional instructions. Notably, this pattern of results in the associative test was

2 replicated when nonwords were substituted by different types of fonts serving as

3 contextual cues (i.e., transformation from a test of word-nonword pairs to a test of

4 word-font pairs, see Naveh-Benjamin, 2000, Experiment 3).

5 In another experiment that utilized the similar procedures for the study of

6 name-face pairs (Naveh-Benjamin et al., 2009), younger and older participants were

7 told to attend to faces, names and the relations between them in preparation for the

8 upcoming item and associative tests of recognition memory under the intentional

9 instructions, and were not told about any of the upcoming tests under the incidental

10 instructions. Instead, they performed an incidental learning exercise that involved

11 the evaluation of how well matched the different faces and names were when

12 compared with each other. Results from the first experiment that implemented

13 intentional learning showed that both age groups were equivalent in the recognition

14 of both names and faces but younger adults outperformed older adults in the

15 associative test. Unlike what Naveh-Benjamin et al. (2000) found, the younger

16 adults were less able to direct the intentional instructions towards an improved

17 learning of face-name associations, showing a noticeable decline in recognition

18 performance in the associative test relative to the item tests. However, older adults

19 exhibited an even greater decline in their associative memory performance relative

20 to their item memory ones, and that suggests that they encountered more

21 difficulties than the younger adults in the implementation of the connective

22 strategy proposed by the intentional instructions (see Figure 1.2). This significant 


\section{AGING AND ASSOCIATIVE MEMORY}

1 interaction between age group and test was not duplicated when incidental

2 instructions were administered in the second experiment. Incidental learning led to

3 similar rates of decline in recognition memory performance for both age groups

4 when deducting their lower associative test scores from higher item/component

5 scores (Figure 1.2). These results were similar to those of Naveh-Benjamin et al.

6 (2000) that showed that incidental instructions did not lead to differential effects on

7 item and associative memory performance.

8 Taken together, these studies suggested that older adults were less able to

9 utilize the connective/relational strategy that was advocated by intentional

10 instructions to improve their episodic memory of word-nonword pairs. They also

11 faced more difficulties than the younger adults at directing the same type of

12 strategy towards the encoding of name-face pairs. This could mean that older adults

13 are either deficient at the effective use of a given strategy or at the production of

14 other strategies that are not task-relevant. Further evidence for these possibilities

15 could be seen from the recognition test results which showed a consistent age group

16 difference with regards to the recognition of distractor pairs (i.e., randomly

17 rearranged pairs) but not to that of originally studied pairs. The relatively higher

18 proportion of false alarms (i.e., falsely recognizing distracter pairs as correct)

19 committed by older adults suggest that they are over-relying on the process of

20 familiarity when retrieving the details of the individual components. As familiarity

21 is an automatic/implicit process that operates without the need of contextual

22 information (Yonelinas, 2002), it is possible that older adults' dependence on 
AGING AND ASSOCIATIVE MEMORY

1 familiarity interfered with their correct recognition of paired items, notably name-

2 face pairs, under intentional instructions. In consideration that the associative

3 recognition memory test utilized by Naveh-Benjamin and colleagues rests on the

4 premise of recollection, which stipulates that an item is retrieved simultaneously

5 with its context, the next section shall address how older adults' associative memory

6 deficit is mediated by familiarity and recollection.

7

\section{CONTRIBUTIONS OF FAMILIARITY AND RECOLLECTION}

\section{PROCESSES}

In item recognition memory tests, familiarity and recollection processes are usually differentiated based on the use of "remember" and "know" responses

(Tulving, 1985). The former requires participants to report about whether they had recollected an item (i.e., based on recalling its exact appearance) whereas the latter enquires about whether they knew that the item had been previously studied (i.e., based on a gist knowledge of it without recalling its features in detail). There is converging evidence from numerous aging studies that suggest that people's ability to use recollection-based processes to retrieve learned information declines with age, but their corresponding ability to use familiarity-based processes does not (e.g., Bastin \& Van der Linden, 2003; Hay \& Jacoby, 1999; Jennings \& Jacoby, 1993; Light et al., 2004; Maylor, 1995). Studies that endeavored to show the qualitative difference between familiarity and recollection demonstrated that "remember" 


\section{AGING AND ASSOCIATIVE MEMORY}

1 responses were more prevalent than "know" responses in associative memory

2 recognition tests whereas the reverse trend occurred in the item memory tests

3 (Hockley \& Consoli, 1999). Notably, studies which examined receiver-operating

4 characteristics (ROCs) in recognition memory assessments-functions that relate

5 hits (i.e., correct recognition of old items) to false alarms (incorrect recognition of

6 lures)—showed that a curvilinear function applied to the modeling of familiarity

7 judgments whereas a linear function applied to the modeling of recollection

8 judgments (e.g., see Yonelinas, 1997). These findings were consistent with dual

9 process theories that proposed memory judgments to be contingent on two

10 qualitatively different processes of systems (e.g., Atkinson \& Juola, 1974, Jacoby \&

11 Dallas, 1981; Mandler, 1980). Specifically, the different functions computed by

12 Yonelinas (1997) based on his experimental data implicated that item judgments

13 depended on a combination of familiarity and recollection whereas associative

14 judgments depended on recollection only.

To understand how the differential reliance on familiarity and recollection

17 be regarded as contributing to high performance in item recognition but low performance in associative/paired recognition. This is due to the familiar-looking

19 appearing of recombined distractor pairs (i.e., pairs created from the random

20 rearrangement of formerly studied items) that will entice the participant to

21 recognize them erroneously as previously studied pairs. Such errors are most likely

22 to occur in the absence of recollection processes that counter the effect of this 
AGING AND ASSOCIATIVE MEMORY

1 automatic strategy that does not elaborate on the links between encoded items. In

2 this way, the findings of Naveh-Benjamin et al. (2009) of older adults making more

3 false alarms than younger adults in responding to recombined name-face pairs

4 could be interpreted as an over-reliance on familiarity-based processes. This

5 potential over-reliance on familiarity could also reflect older adults' under-

6 recruitment or difficulties with using recollection-based processes or strategies.

7 Other studies showing similar trends of higher rates of false alarms committed by

8 cognitively intact older adults in the associative recognition of conjunction pairs of

9 faces (i.e., recombination of previously seen faces) (Rhodes, Castel, \& Jacoby, 2008)

10 and random landmark-scene combinations (i.e., landmarks set against scenes that

11 are not observed from navigating a virtual environment) (Head and Isom, 2010)

12 gave more evidence to support the view that older adults are deficient at adopting a

13 "recall-to-reject" cognitive process or strategy. Interestingly, it is also worth noting

14 that familiarity-based processes, which are resistant to an age-related decline,

15 hampered rather than reinforced older adult's associative memory.

\section{EFFECTS OF DIVIDED ATTENTION ON CONTROLLED}

\section{PROCESSES}

Apart from the types of instructions and familiarity- and recollection-based

21 processes, the effects of divided attention on memory performance are of great

22 concern to memory researchers. Some typical situations when attention becomes 


\section{AGING AND ASSOCIATIVE MEMORY}

1 divided occur when one gets introduced to a new acquaintance and has to register

2 his/her name amidst competing social cues, and when one attempts to retrieve

3 information while carrying out a second complex task (e.g., keeping track of one's

4 location on the GPS device while driving). These situations and many others deter

5 people from focusing on one task alone and will affect them adversely if they need to

6 retrieve information from some of the tasks subsequently.

The studies on divided attention generally examined its effects at the encoding and retrieval stages. Based on dual-task paradigms in which participants (mainly

9 college- and middle-aged) performed two tasks simultaneously, previous research

demonstrated decrements in memory performance on both primary (memory-based)

11 and secondary (distractor) tasks under divided attention condition relative to full

12 attention condition (e.g., Baddeley, Lewis, Eldridge, \& Thomson, 1984; Craik,

13 Govoni, Naveh-Benjamin, \& Anderson, 1996). With respect to retrieval, divided

14 attention has been shown to minimally affect performance on the primary memory

15 performance task, despite producing a similar decline in secondary task

16 performance. This shows that retrieval processes were relatively more resistant to

17 the interference posed by divided attention (Craik et al., 1996).

Aging studies that compared the extents to which memory performance were

19 disrupted by divided attention for younger and older adults produced mixed results

20 with regards to the interruption of encoding processes by divided attention. When

21 encoding information under divided attention situations, although some studies

22 found larger memory decrements for older than for younger adults (e.g., Park, 


\section{AGING AND ASSOCIATIVE MEMORY}

1 Smith, Dudley, \& Lafronza, 1989; Salthouse, Rogan, \& Prill, 1984), there were many other studies that showed similar levels of memory decrements for both age

3 groups (e.g., Anderson, Craik, \& Naveh-Benjamin, 1998; Baddeley, Logie, Bressi,

4 Della Sala, \& Spinnler, 1986; Light \& Prull, 1995; Park, Puglisi, \& Smith, 1986). In

5 contrast, the retrieval of information under divided attention produced findings

6 which were more congruous with one another. Like the younger adults, older adults

7 have been shown to be minimally affected by secondary task performance during

8 information retrieval (Anderson et al., 1998; Macht \& Buschke, 1983; Nyberg,

9 Nilsson, Olofsson, \& Bäckman, 1997; Park et al., 1989; Whiting \& Smith, 1997).

However, older adults showcased attentional costs based on their relatively poorer secondary task performance (Anderson et al., 1998; Craik \& McDowd, 1987; Macht \& Buschke, 1983; Whiting \& Smith, 1997). Such costs generally refer to the decrements in performance when the secondary task was performed under divided attention compared to when it got performed under full attention (see Craik, NavehBenjamin, \& Anderson, 1998). The presence of these attentional costs for older adults suggests that they have reduced attentional resources for episodic memory formation (Craik, 1982, 1983; Craik \& Byrd, 1982), which led to their difficulties with the successful completion of the concurrent task.

The first study that systematically examined the age-related effects of divided attention at both encoding and retrieval on memory and secondary task performance was conducted by Naveh-Benjamin, Craik, Guez, \& Kreuger (2005). In that study, the authors applied a cued-recall paradigm that was regarded as 


\section{AGING AND ASSOCIATIVE MEMORY}

1 imposing high demands for cognitive resources both at encoding and at retrieval

2 (see Craik et al., 1996). The primary associative memory task involved the learning

3 of word-pairs that were presented aurally within 3 seconds (followed by a 3 second

4 delay before another word pair was presented) while the secondary task involved

5 the following of a moving green asterisk with a white dot that was controlled by the

6 participants. To perform the latter task well, participants had to move the white dot

7 with the mouse and keep it as close as possible to the asterisk while following it.

8 The dependent variable for this task is being recorded as the distance (in

9 millimeters) between the dot and the asterisk. In the full attention condition, these

10 two tasks were performed separately, with performance on the secondary tracking

11 task treated as the baseline. In contrast, in the divided attention condition, the two

12 tasks were performed simultaneously under the instructions to pay equal attention

13 to each. Retrieval was conducted under full attention for both conditions and

14 participants had to produce the target words after being cued with their affiliates

15 within 6 seconds on each trial.

In the analysis of results, the authors addressed the question of whether there

17 are specific processes during encoding and retrieval that consume more resources in

18 older adults by dividing up the encoding and retrieval periods of each word pair (6

19 seconds each) into three temporal phases respectively. For encoding, these phases

20 were stimulus perception (the first 650 milliseconds), stimulus elaboration (the next

211.5 seconds), and learning (the final 3.85 seconds). For retrieval, its phases spanned

22 the same periods as those of encoding and referred to cue perception, cue 


\section{AGING AND ASSOCIATIVE MEMORY}

1 elaboration, and search plus retrieval mode. The comparison of younger and older

2 adults with respect to attentional costs (i.e., secondary tracking costs), computed as

3 the arithmetic difference between single- and dual-task performance, demonstrated

4 significant age group differences in the elaboration and learning phases of encoding,

5 as well as across the three phases of retrieval, with the age group difference being

6 the most salient during the second retrieval phase (see Figure 1.3). Overall,

7 attentional costs are comparatively greater for older adults at retrieval than at

8 encoding. When the data was analyzed based on whether the words are successfully

9 or unsuccessfully retrieved, a similar trend of age group differences across the

10 retrieval phases were produced. This suggests that searching and producing the

11 target words to the cues was attentionally demanding irrespective of whether they

12 were properly recalled. The common trend of higher increases in attentional costs

13 shown by the older adults from the first to the second phase of encoding and

14 retrieval suggest that reduced attentional resources have substantial negative

15 effects on older adults' rehearsal of the stimuli upon first exposure and their

16 subsequent search processes. Along with the higher attentional costs incurred by

17 older adults at the final retrieval phase, the findings implicate that cue-elaboration,

18 word search and production, and maintaining a retrieval mode become difficult and

19 resource demanding in older age.

To find out whether these findings were consistent with the proposed

21 associative memory deficit in older adults, Kilb \& Naveh-Benjamin (2007) carried

22 out a study that compared the item and associative memory performance of younger 


\section{AGING AND ASSOCIATIVE MEMORY}

1 and older adults under full and divided attention conditions. In the item/component

2 test, they applied a forced-choice paradigm that balanced the amount of stimuli (i.e.,

3 words) presented on each item trial with that presented on each associative trial.

4 The words appeared in pairs and studied words were presented on the left and right

5 sides of the screen in equal proportions. The participants pressed two keys to

6 respond to target words appearing on the left and right sides of the screen

7 respectively. In the associative test, paired words appeared on each trial and

8 participants had to press a key if they recognized the pair as previously studied and

9 another key if they recognized it as a recombination of previously studied words. As

10 for the secondary/concurrent task devised to induce divided attention, it was an

11 auditory response task that required participants to discriminate among three

12 pitches. The tones were presented sequentially and participants had to press one of

13 three buttons that correspond to the appropriate tone.

14 The results demonstrated an associative deficit (i.e., the difference between

15 item and associative memory performance) under both full and divided attention

16 condition for older adults but not for younger adults, who only demonstrated similar

17 rates of decline in item and associative memory performance when comparing the

18 full and divided attention conditions. Despite demonstrating that older adults

19 suffered from an associative deficit under divided attention, the findings could not

20 be interpreted as supporting the argument that reduced attentional resources

21 mediate older adults' associative memory. This is due to the surprising finding of

22 older adults showing an unexpected lower degree of associative deficit under the 
AGING AND ASSOCIATIVE MEMORY

1 divided attention condition than under the full attention condition. Unlike the item

2 memory performance that declined under divided attention, associative memory

3 performance remained fairly stable across both attentional conditions. These

4 peculiar findings suggest that the attentional costs experienced by older adults do

5 not necessarily have to affect their studying of combined units of information. More

6 importantly, the findings provided reasons to support the involvement of other

7 mechanisms that are involved in the associative memory deficit of older adults.

8 Such mechanisms refer to explicit strategies and automatic binding processes that

9 may exert greater influences than attentional resources in determining the

10 integrity of associative memory in younger and older adults.

\section{STRATEGIES FOR IMPROVING ASSOCIATIVE MEMORY}

The need to understand the role of conscious strategies for the encoding and retrieval of episodic/associative memories is pertinent in view of the studies that showed older adults to make greater false recognition of recombined distractor pairs

17 than younger adults (e.g., Head \& Isom, 2010; Naveh-Benjamin et al., 2009; Rhodes et al., 2008, as aforementioned). These findings not only suggest that older adults are over-relying on habitual or automatic processes when processing such misleading information, but are also probably suffering from an inability to utilize

21 appropriate retrieval processes. These retrieval processes, as well as

22 complementary encoding process, can be characterized as associative learning and 


\section{AGING AND ASSOCIATIVE MEMORY}

1 recall strategies that require a considerable amount of cognitive effort. These

2 strategies are proposed based on the assumption that older adults either do not use

3 them or use them ineffectively (Kausler, 1994). Hence, providing older adults with

4 the opportunities to learn and practice them may be a way to improve their

5 associative memory.

6 To examine the potential benefits of strategies, a study by Naveh-Benjamin,

7 Brav, \& Levy (2007) compared three conditions where participants were given

8 intentional instructions only (i.e., no specific strategy), associative strategy at

9 encoding, and associative strategy as both encoding and retrieval. The participants

10 studied lists of unrelated word pairs and subsequently did item and associative

11 recognition tests. Distractor items were unrelated to the target words and were

12 matched in terms of linguistic properties (i.e., word frequency, semantics, and

13 phonemes). In line with the conventional practice, distractor pairs were formed

14 based on randomly re-pairings of the component words that constitute the studied

15 word pairs. During the study phase, participants are given intentional instructions

16 under all conditions. Under the condition where no specific strategy was given,

17 participants were told about the nature of the upcoming tests and to study the word

18 pairs in order to stay prepared. In the second condition, another group of

19 participants were told about using an associative strategy to link together each pair

20 of words using a sentence that meaningfully connects them. Finally, a third group of

21 participants was told not just to use sentence connectors during encoding but to re-

22 apply them during retrieval to help them decide on whether a word or a pair had 


\section{AGING AND ASSOCIATIVE MEMORY}

1 been studied. The authors designed this third condition based on the view that the

2 associative strategic deficit of older adults could occur at both encoding and

3 retrieval phases (Naveh-Benjamin et al., 2005), and that if such a deficit indeed

4 exists under both scenarios, a suggestion for consistent strategy use would be of 5 optimal benefit for older adults.

6 The findings in terms of the index of hits minus false alarms showed that older

7 adults exhibited the usual associative memory deficit under the first condition

8 where only intentional instructions was given but showed marked improvement in

9 associative recognition under the two strategy conditions-an improvement that

was comparatively greater than that shown by the younger adults (see Figure 1.4).

11 Notably, the improvement appear to be additive, with steady increments in

12 associative performance for older adults from the first condition where no associative strategy was given to the third condition where strategy use was

14 encouraged at both encoding and retrieval.

Importantly, these findings suggest that the use of relevant strategies enhanced older adults' engagement with controlled processes or attentional

17 resources. They related well to the earlier findings by Naveh-Benjamin et al. (2005) that showed older adults to exhibit higher attentional costs (i.e., poorer performance

19 on the secondary task due to reduced attentional resources) than younger adults

20 when the strategic use of sentence or imagery mediators occurred during both

21 encoding and retrieval. Moreover, this view of effortful processing being linked to

22 strategy use was supported by previous studies which showed that age-related 


\section{AGING AND ASSOCIATIVE MEMORY}

1 differences in episodic memory were diminished when older adults were told to

2 deliberate about the relations between an item and its context at retrieval (Glisky,

3 Rubin, \& Davidson, 2001), and to utilize meaningful sentences to connect

4 contextually related picture pairs at encoding (Smith et al., 1998).

5 Together, the findings by Naveh-Benjamin and colleagues suggest that older

6 adults' associative deficit was due to their inability to readily generate associative

7 strategies—a production deficiency—rather than an inability to use strategies

8 efficiently. According to the latter view, older adults' associative deficit stemmed

9 primarily from their irregular use of an associative strategy, which subsequently

10 leads to its inefficient use under circumstances that require it (e.g., see Craik \&

11 Rabinowitz, 1985; Dunlosky \& Hertzog, 1998; Erber, Galt, \& Botwinick, 1985).

12 Consequently, even when older adults are able to produce a particular associative strategy successfully, they will not reach the same level of performance as younger

14 adults simply due to their inexperience with utilizing it in an efficient or effective

15 way. An example would be older adults forming fewer sentences than younger

16 adults that describe actions which connected the words in a pair together (Smith et

17 al., 1998). This possibility of inefficiency in strategy use thereby offers reason for caution in the belief that intentional instructions to use associative strategies will

19 automatically improve older adults' associative memory. Training in the efficient

20 creation of sentences or images relating word pairs together may be as important as

21 the instructions to use specific strategy use, if not more. Hertzog, Price, and

22 Dunlosky (2012) showed that although younger and older adults were comparable 
AGING AND ASSOCIATIVE MEMORY

1 in the production of an interactive imagery strategy that represents word pairs

2 through imaginations of meaningful actions or activities, older adults were

3 relatively less accurate in the cued recall of the target words. The authors also

4 showed that older adults were less likely than younger adults to utilize the

5 interactive imagery strategy again in the learning of a second list of word pairs,

6 suggesting that they are less confident or effective at implementing such a strategy.

7 Interestingly, even though older adults are poorer at executing the interactive

8 imagery strategy than younger adults, its use eliminated older adults' associative

9 memory deficit (Patterson \& Hertzog, 2010). Instructing older adults to form images

10 of the individual words in each pair prior to forming interactive imageries improved

11 their memory performance (on both item and associative tasks) to levels that were

12 slightly below the memory performance of younger adults.

\section{PRESERVATION OF IMPLICIT ASSOCIATIVE MEMORY IN OLD} AGE

Aside from considering the influences of recollection-based, effortful and strategic processes on encoding and retrieval, it is also important to consider the

19 role of familiarity-based automatic processes in associative memory formation. In

20 contrast to the strategic-effortful processes that produced prominent age group

21 differences, many studies have demonstrated that the operation of automatic

22 processes generally remains intact in old age (e.g., Dew \& Giovanello, 2010; Jacoby, 


\section{AGING AND ASSOCIATIVE MEMORY}

1 Toth, \& Yonelinas, 1993; Jennings \& Jacoby, 1993; Hay \& Jacoby, 1999; Kessels,

2 van Doormaal, \& Janzen, 2011; Koutstaal, 2003; Titov \& Knight, 1997). The

3 classical paradigm used for identifying the preservation of automatic processes in

4 old age was based on a word stem completion task that operates on a process-

5 dissociation procedure (see Jacoby et al., 1993). The word stem completion task

6 requires the completion of words that have their first three letters presented (e.g.,

7 mot--). Such words can be old words that were previously studied or new words that

8 are freely generated by the participants. The process-dissociation procedure

9 determines the types of words that the participants should generate. It is based on

10 either an inclusion or exclusion test of the memory of previously studied words. In

11 the inclusion test, the word stem is accompanied by a message of "old", and

12 participants were instructed to use the stem as a cue for recall of a studied word;

13 and to complete the stem with the first word that came to mind if they could not do

14 so. In this way, the inclusion test is akin to a test of cued recall with additional

15 instructions to guess when recollection fails. On the other hand, the exclusion test

16 has the message "new" displayed alongside the word stem and participants were

17 instructed to use the stem as a cue for recall of a studied word but not to apply the

18 recalled word to complete the stem. In other words, participants were told to

19 exclude the studied words that they recalled and complete the stems only with new

20 words that had not been studied.

When an inclusion or exclusion test immediately followed presentation of it a

22 particular word, no significant age differences were observed, indicating that older 


\section{AGING AND ASSOCIATIVE MEMORY}

1 adults understood and followed instructions. However, when numerous items

2 intervened between the presentation of a word and its inclusion or exclusion test,

3 older adults performed significantly poorer than younger adults. Namely, in the

4 inclusion test, older adults completed less word stems correctly than younger

5 adults, but completed more word stems correctly under the exclusion test. The

6 poorer performance of older adults in the inclusion test could be explained by the

7 age-related decline in recollection-based processing, whereas their better

8 performance on the exclusion test could be explained by their overreliance on

9 automatic processes that compensated for their deficits in recollection. These explanations were backed up by the quantitative estimates of the conscious and

11 unconscious influences of memory, which showed equally high estimates of

12 unconscious processing by both age groups, but relatively lower estimates of

13 conscious processing by older adults (Jacoby et al., 1993).

14 While the word stem completion paradigm with inclusion and exclusion tests

15 examined the dissociation between automatic and controlled processes in affecting

16 item memory, subsequent research by Hay and Jacoby (1999) dissociated the

17 influences of these processes on associative memory. Their experiment was

18 separated into three phases. In the first phase, younger and older participants were

19 exposed to associatively related word pairs (e.g., organ-music, organ-piano) at

20 varying frequencies (e.g., $25 \%$ versus $75 \%$ ) to induce habits of linking cue words to

21 target words that appear at higher frequencies (e.g., linking organ to music, which

22 appeared on $75 \%$ of the trials). In the second phase, participants studied short lists 


\section{AGING AND ASSOCIATIVE MEMORY}

1 of word pairs that had studied pairs that previously appeared at high and low

2 frequencies, labeled as congruent and non-congruent pairs respectively. In the third

3 testing phase, participants were cued with the first word of a pair (e.g., organ-__)

4 and told to fill in the blank with the studied word that they could recall. Results

5 showed that both age groups were alike in reporting high frequency target words

6 (e.g., music) for completing congruent pairs but older adults were more likely to

7 erroneously recall the same target words to complete incongruent pairs. The

8 authors explained these results with referral to a dual-process model that propose

9 older adults to rely more on their habit or tendency to automatically link cues with

10 their high frequency counterparts for completing incongruent word pairs. This

11 model suggests that automatic processing by older adults is induced through a

12 repetition of familiar information and that it is older adults' preferred mode of

13 retrieval under circumstances when recollection fails.

14 Further research by Koutstaal $(2003,2006)$ showed that this automatic habit

15 of combining frequently seen items is analogous to the acquisition of gist knowledge

16 by older adults (i.e., knowing that items belong to the same concepts or categories

17 without remembering their specific details). Koutstaal (2003) tested younger and

18 older adults on the recognition of specific objects and the association of their

19 different exemplars to their common categories. Results showed that younger adults

20 were better than older adults at recognizing the same exemplars (i.e., objects that

21 were identical to those that were studied) as compared to different exemplars

22 (alternative objects that belong to the same category as the studied object, e.g., two 


\section{AGING AND ASSOCIATIVE MEMORY}

1 different umbrellas) but no significant age group difference occurred with regards to

2 recognizing the two different types of exemplars as belonging to the same

3 conceptual category. There was also no age group difference in repetition priming,

4 which requires making rapid decisions about whether the exemplars were larger

5 than their real-world referents; both age groups exhibited larger priming effects

6 (i.e., faster responses to exemplars than to lures/distractors) in responding to the

7 same exemplars than to different exemplars. These results suggest that although

8 older adults encoded details about the objects, they used them less effectively than

9 the younger adults under the context that requires the recollection of their specific

10 features. They were further supported by subsequent findings by Koutstaal (2006)

11 showing that the sensitivity to gist knowledge was virtually identical between both

12 younger and older adults under category-based recognition. Notably, older adults

13 demonstrated themselves to be only slightly worse than the younger adults at

14 flexible remembering - typified by switching between automatic and controlled-

15 effortful processes to suit the optimal recollection of gist and item-specific

16 knowledge respectively.

17 The engagement of gist knowledge for making verifications about different exemplars from a common category can also be likened to reliance on previous in

19 order to remember associations. Several studies by Castel and colleagues (e.g.,

20 Castel, 2005, 2007; McGillivray \& Castel, 2010) have shown that when older adults

21 had to bind together several pieces of information that they are well acquainted

22 with (e.g., grocery items and prices, faces and ages of different people, sets of 
AGING AND ASSOCIATIVE MEMORY

1 numerical and object information), they were able to apply their previous knowledge

2 or expertise and demonstrate little or no age-related associative deficit. Retrieving

3 information from a knowledge base also reduces older adults' need to engage in

4 processes that require the conscious engagement of fluid intelligence (i.e., novel

5 problem solving, abstract reasoning), and deters older adults' daily functioning from

6 being over-affected by the age-related decline in fluid intelligence (Salthouse, 2004).

7 Cumulatively, these studies showed that older adults are able to use automatic

8 processes in the forms of habit, gist or abstract knowledge, together with previous

9 knowledge that is well-honed through numerous exposures. Although these

10 automatic processes benefitted older adults in the retrieval of items that were high

11 related in terms of frequency and concept, they adversely affected older adults'

12 recognition of items and paired associates that required the processing of fine-

13 grained details. This shows that older adults' use of automatic processes for the

14 encoding and retrieval of associative memory is optimally suited for circumstances

15 that do not require controlled-effortful processes.

Apart from all the behavioral evidences that implicated the age-related

21 decline in associative memory, it is important to understand the functional and

22 structural changes in the brain that contribute to older adults' poorer 


\section{AGING AND ASSOCIATIVE MEMORY}

1 associative/episodic memory. The brain region that is proposed to be a 'binder' of

2 memories is the hippocampus (Cohen et al., 1999), and numerous neuroimaging

3 studies that examined associative learning have implicated it to be involved in the

4 automatic binding of information (e.g., Cohen \& Eichenbaum, 1993; Eichenbaum,

5 2003; Eichenbaum \& Bunsey, 1995; Henke, Buck, Weber, \& Wieser, 1997; Kroll,

6 Knight, Metcalfe, Wolf, \& Tulving, 1996; Wallenstein, Eichenbaum, \& Hasselmo,

7 1998). These automatic binding processes, normally activated under incidental

8 learning conditions, have been shown to be negatively affected in older adults (e.g.,

9 see Grady et al., 1995; Moscovitch, 1994; Mitchell, Johnson, Raye, \& D'Esposito,

2000). For instance, Mitchell, Johnson, Raye, and D'Esposito (2000) found that older

11 adults exhibited lower hippocampal activation than younger adults when learning

12 the associations between items and their locations as compared with the items'

13 individual features. Moreover, they revealed the same pattern of age-related

14 differences in activation in the medial prefrontal cortex (mPFC) with older adults

15 having lower activation. Consistent with proposals of the hippocampus and mPFC

16 being the neural correlates of automatic and strategic-effortful binding processes

17 respectively (Moscovitch \& Winocur, 1992, Moscovitch, 1994), these findings

18 interestingly suggest that the processing of associative or episodic information may

19 engage parallel but distinct binding processes in both the $\mathrm{mPFC}$ and the

20 hippocampus.

21 The close links between the mPFC and the hippocampus have also been

22 highlighted by neurocomputational research which showed that senescent changes 


\section{AGING AND ASSOCIATIVE MEMORY}

1 in the neuromodulatory mechanisms underlying the fronto-hippocampal circuitry

2 play a basic role in accounting for the associative deficit of older adults (Li, Naveh-

3 Benjamin, \& Lindenberger, 2005). More importantly, MRI studies on older adults

4 have related reductions in hippocampal activation and volume with reduction in

5 memory performance over a 6 year period (Persson et al., 2012), and proposed that

6 the preservation of intact associative memory among some high-functioning older

7 adults may be attributed to the preservation of hippocampal function together with

8 a high level of PFC responsivity (Pudas et al., 2013).

9 Furthermore, numerous studies have interpreted the positive relationship between additional recruitment of certain brain regions-particularly the bilateral

11 recruitment of $\mathrm{PFC}$ among older adults which contrasted with its unilateral

12 recruitment among younger adults—and better memory performance as evidence

13 for neural compensation, and negative relationships as against this interpretation

14 (e.g., Cabeza, Anderson, Locantore, \& McIntosh, 2002; Cabeza, et al., 1997; Davis,

15 Kragel, Madden, \& Cabeza, 2012; Duarte, Henson, \& Graham, 2008; Dulas \&

16 Duarte, 2012; Eyler et al., 2011; Huang, Polk, Goh, \& Park, 2012; Morcom \&

17 Friston, 2012; Rajah \& D'Esposito, 2005; Rosen et al., 2002). Depending on the

18 demand characteristics of a cognitive task, older adults' level of PFC activation can

19 be either reduced or elevated relative to younger adults (Grady 2012; Spaniol \&

20 Grady, 2012). While some studies found that younger adults have higher PFC

21 activation than older adults during encoding (e.g., Anderson et al., 2000; Cabeza,

22 Anderson, Mangels, \& Nyberg, 2000), many others have documented a greater 


\section{AGING AND ASSOCIATIVE MEMORY}

1 bilateral activation of the PFC in older than in younger adults (e.g., Cabeza, 2002;

2 Eyler et al., 2011; Grady et al., 1995; Park, Polk, Mikels, Taylor, \& Marshuetz,

3 2001; Park \& Reuter-Lorenz, 2009; Rajah \& D'Esposito, 2005; Reuter-Lorenz, 2002).

4 This greater bilaterality of PFC activity is dubbed Hemispheric Asymmetry

5 Reduction in OLDer adults (HAROLD) (Cabeza, 2002), and has been seen as giving

6 support for the notion that older adults can compensate for the decline in cognitive

7 resources by implementing adaptive strategies or reserve resources (Cabeza \&

8 Dennis, 2013; Collins \& Mohr, 2013; Freund \& Baltes, 2002; Steffener \& Stern,

9 2012). Nonetheless, there have been concerns that the additional recruitment of the

10 right $\mathrm{PFC}$ for the encoding of paired associates (i.e., word pairs) may reflect the

11 deleterious effect of dedifferentiation, which is characterized by the loss of

12 specification of cortical recruitment to regions supporting task-relevant processes

13 (see de Chastelaine, Wang, Minton Muftule, \& Rugg, 2011; see also Grady, 2012, for

14 a review). Alternatively, dedifferentiation may also arise as an outcome of a decline

15 in the functional integrity of neural networks that accompanies normal aging

16 (Grady, 2012).

17 In the study by de Chastelaine et al. (2011), older adults was found to exhibit

18 higher activation in the right $\mathrm{PFC}$ during the recognition of word pairs. In contrast

19 to the improvement in memory performance as what the HAROLD model will

20 predict, activation in the right PFC negatively correlated with associative memory

21 performance, and the authors interpreted this finding as evidence for the

22 inadequacy of the compensatory process that preserves memory performance in the 
AGING AND ASSOCIATIVE MEMORY

1 presence of age-related neural decline. They primarily explained this finding based

2 on the notion of 'partial' compensation—which relates older adults' higher

3 recruitment of the right $\mathrm{PFC}$ to the engagement of processes that compensate for

4 the inability of the left PFC to meet all the online demands of the study task.

5 However, this higher activation in the right PFC, unlike that in the left PFC,

6 contributes little or nothing to episodic memory encoding. Despite the abstractness

7 of this explanation, the "partial compensation hypothesis" has also been favored by

8 other researchers who view compensatory processes as not being able to completely

9 offset the deleterious effect of neural decline or insult (e.g., Bäckman \& Dixon, 1992;

10 Buckner, 2004; Daselaar \& Cabeza, 2005; Duarte, Henson, \& Graham, 2008;

11 Duverne et al., 2009; Persson et al., 2006; Stern et al., 2005; Zarahn et al., 2007).

12 Importantly, the consideration of partial neural compensation highlights a need for

13 future research to investigate the influences of individual differences in cognitive

14 function on the self-initialization of compensatory processes. It is possible that

15 partial or full neural compensation is more readily endorsed by older adults with

16 more intact or better preserved cognitive functions than those without.

17

\section{LIMITATIONS AND FUTURE DIRECTIONS}

Based on the studies that were reviewed, an age-related decline in the strategic-effortful or recollection-based processing has a greater detrimental impact on the encoding and retrieval of associative memories of older adults when 


\section{AGING AND ASSOCIATIVE MEMORY}

1 compared with automatic or familiarity-based processes that are relatively well-

2 preserved in old age. Although the majority of these studies highlighted the

3 pertinence of conscious mechanisms and strategies for the memory of paired

4 associates, they are not unequivocal in attributing older adults' poorer encoding and

5 retrieval of paired associates to a deficiency in information processing resources.

6 This is exemplified by Kilb and Naveh-Benjamin's (2007) surprising finding of older

7 adults having an almost equivalent level of associative memory performance under

8 the divided attention condition as that under the full attention condition,

9 culminating in an associate memory deficit that was larger under the former

10 condition than under the latter condition. Such findings are at odds with the

11 perception that dual task conditions limit the allocation of attentional resources for

12 processing bound information and suggest that individual differences among the

13 older adults in terms of other cognitive abilities may play a part in determining

14 their relatively intact associative memory performance under the divided attention

15 condition.

Alternatively, it may also mean that the concurrent/secondary tasks used in

17 some of the aforementioned studies are not demanding enough to affect subsequent associative memory differentially under the two types of attention conditions. For

19 instance, the effect of such concurrent tasks would be minimal for older adults who

20 implemented non-conventional strategies or heuristics that differed from an

21 effortful associative learning approach. Therefore, future research should seek to

22 design more suitable concurrent tasks that adequately intervene with older adults' 


\section{AGING AND ASSOCIATIVE MEMORY}

1 informational processing, as well as address how individual differences in cognitive

2 functions could affect older adults' associative or episodic memory.

3 Future research on the effects of individual differences is important since

4 previous studies have shown that the differential production of associative

5 strategies affects subsequent recognition of paired associates (Naveh-Benjamin et

6 al., 2007) and that different levels of effective strategy use are positively related to

7 different levels of word recall (Lachman \& Andreoletti, 2006). Moreover, many

8 studies have shown that there are age differences in metacognitive self-efficacy-

9 generally defined as the belief in one's ability to complete a task successfully (see,

10 e.g., Hertzog \& Hultsch, 2000; Lachman, 2006; McDougall \& Kang, 2003; Rebok \&

11 Balcerak, 1989)—and that it could positively affect memory performance through

12 the mediating effect of strategy use (Hertzog, Dunlosky, \& Robinson, 2009;

13 Lachman \& Andreoletti, 2006). This means that individual differences in the

14 generation or efficiency of use of memory strategies is under the higher influence of

15 memory self-efficacy or perceived control of memory performance, and that strategy

16 use per se is not the prime actor in bringing about optimal memory performance.

17 Older adults with higher self-efficacy or perceived control of their memory functions generally perform better than their counterparts with lower self-efficacy/perceived

19 control (see, e.g., de Frias et al., 2003; Hertzog, Dunlosky, \& Robinson, 2009;

20 Lachman \& Agrigoroaei, 2012; Lachman \& Andreoletti, 2006); and older adults who

21 are better at monitoring their progress towards goals in a memory task (i.e.,

22 memory monitoring) have been shown be more likely to use memory strategies 


\section{AGING AND ASSOCIATIVE MEMORY}

1 effectively (Hertzog, Price, \& Dunlosky, 2012). In view that older adults can be

2 trained to self-regulate or monitor their metacognition that subsequently led to

3 them having better recall of paired associates (Dunlosky, Kubat-Silman, \& Hertzog,

4 2003), just like the way that they can be trained to use associative memory

5 strategies (Naveh-Benjamin et al., 2007), future studies could focus on integrating

6 training regimens in both metacognitive monitoring and memory strategy use for a

7 double-pronged approach to improving older adults' episodic or associative memory

8 performance.

9 Furthermore, a better knowledge of individual differences in metacognitive self-regulation and strategy use among older adults may give us the evidence to

11 clarify the contentious issue of neuronal compensation in the prefrontal lobes. A

12 direction that future neuroimaging research can embark on is to figure out whether

13 bilateral activation in the prefrontal lobes of older adults is associated with higher

14 metacognitive monitoring and effective strategy use.

Finally, it is worth noting that most of the interventions used to distinguish controlled from automatic processes assessed the macrolevel of behavior based on

17 manipulations of study instructions, which included the relevant memory strategies to adopt (e.g., Naveh-Benjamin et al., 2005, 2007; Patterson \& Hertzog, 2010),

19 without a more fine-grained analysis of the microlevel features of behavior.

20 Microlevel analysis refers to the studies that utilized dual-task paradigms to

21 implicate a constraint on cognitive resources under the divided attention condition

22 (e.g., Craik, 1982, 1996; Naveh-Benjamin et al., 2005) and studies that examined 


\section{AGING AND ASSOCIATIVE MEMORY}

1 different processes during pre-specified phases of encoding and retrieval (Naveh-

2 Benjamin et al., 2005). Due to the requirements for higher standards of

3 experimental testing and statistical analyses, such studies have not been prevalent,

4 and so future studies can be conducted using more intricate designs to differentiate

5 the components of automatic and controlled processes, and pinpoint their roles in

6 the age-related decline in associative memory.

7

\section{SUMMARY}

Numerous behavioral studies to date examined the roles of automatic and controlled processes in the formation and retrieval of associative memories and generally suggest an age-related decline in controlled processing to account for older adults' associative deficit. These studies showed that older adults are less able than younger adults at: (a) using associative strategies presented to them through intentional instructions; (b) generating associative strategies on their own accord; (c) recalling previously studied items and paired associates based on recollectionbased processes. In spite of older adults' declining cognitive abilities in these aspects, older adults generally preserve their implicit memories of bound information and are capable of forming a "gist" knowledge of items in memory by linking them with high-order concepts or categories. The presence of bilateral prefrontal activation in older adults seems to suggest that they are engaging in compensatory neural resources to ward off the negative effects of the memory 
AGING AND ASSOCIATIVE MEMORY

1 decline. Yet the variability of this bilateral activation across tasks of varying

2 demand characteristics makes the claim of compensatory mechanisms an equivocal

3 one. Individual differences in cognitive functions, metacognitive self-regulation (i.e.,

4 metacognitive self-efficacy and monitoring), and strategic processes (i.e., production

5 and efficiency of use) are likely to produce variation in activation in the prefrontal

6 cortex, as well as in other brain regions like the parahippocampal/hippocampal

7 formation. Further studies employing more rigorous methodologies and fine-grained

8 statistical analyses are needed to investigate the converging influences of these

9 individual differences on the neural, cognitive, and behavioral functioning of older

10 adults. 
AGING AND ASSOCIATIVE MEMORY

\section{REFERENCES}

Anderson, N. D., Craik, F. I. M., \& Naveh-Benjamin, M. (1998). The attentional demands of encoding and retrieval in younger and older adults: I. Evidence from divided attention costs. Psychology and Aging, 13, 405-423.

Anderson, N. D., Iidaka, T., Cabeza, R., Kapur, S., McIntosh, A. R., \& Craik, F. I. M. (2000). The effects of divided attention on encoding- and retrieval-related brain activity: A PET study of younger and older adults. Journal of Cognitive Neuroscience, 12(5), 775-792.

Atkinson, R.C., \& Juola, J.F. (1973). Factors influencing speed and accuracy of word recognition. In S. Kornblum (Ed.), Attention and performance (Vol. 4, pp. 583612). New York: Academic Press.

Bäckman, L., \& Dixon, R. A. (1992). Psychological compensation: A theoretical framework. Psychological Bulletin, 112(2), 259-283.

Baddeley, A. D., Logie, R., Bressi, S., Della Sala, S., \& Spinnler, H. (1986).

Dementia and working memory. Quarterly Journal of Experimental Psychology, 38A, 603-618.

Baddeley, A. D., Lewis, V., Eldridge, M., \& Thomson, N. (1984). Attention and retrieval from long-term memory. Journal of Experimental Psychology: General, 13, 518-540.

Bastin, C., \& Van der Linden, M. (2005). Memory for temporal context: Effects of ageing, encoding instructions, and retrieval strategies. Memory, 13, 95-109. 
AGING AND ASSOCIATIVE MEMORY

1 Bayen, U. J., Phelps, M. P., \& Spaniol, J. (2000). Age-related differences in the use

2 of contextual information in recognition memory: A global matching approach. The Journals of Gerontology, Series B: Psychological Sciences and Social Sciences, 55, 131-141.

Buckner, R. L. (2004). Memory and executive function in aging and AD: Multiple factors that cause decline and reserve factors that compensate. Neuron, 44(1), 195-208.

Cabeza, R. (2002). Hemispheric asymmetry reduction in older adults: The HAROLD model. Psychology and Aging, 17(1), 85-100.

Cabeza, R., Anderson, N. D., Locantore, J. K., \& McIntosh, A. R. (2002). Aging gracefully: Compensatory brain activity in high-performing older adults. NeuroImage, 17(3), 1394-1402.

Cabeza, R., \& Dennis, N. A. (2013). Frontal lobes and aging: Deterioration and compensation. In D. T. Stuss, \& R. T. Knight (Eds.), Principles of frontal lobe function (2nd ed., pp. 628-652). New York: Oxford University Press.

Cabeza, R., Grady, C. L., Nyberg, L., McIntosh, A. R., Tulving, E., Kapur, S., .. . Craik, F. I. M. (1997). Age-related differences in neural activity during memory encoding and retrieval: A positron emission tomography study. The Journal of Neuroscience, 17(1), 391-400.

Castel, A. D. (2005). Memory for grocery prices in younger and older adults: The role of schematic support. Psychology and Aging, 20, 718-721. 
AGING AND ASSOCIATIVE MEMORY

1 Castel, A. D. (2007). Aging and memory for numerical information: The role of specificity and expertise in associative memory. Journals of Gerontology: Series B: Psychological Sciences and Social Sciences, 62B(3), 194-196.

Castel, A. D., \& Craik, F. I. M. (2003). The effects of aging and divided attention on memory for item and associative information. Psychology and Aging, 18, 873885.

Chalfonte, B. L., \& Johnson, M. K. (1996). Feature memory and binding in young and older adults. Memory \& Cognition, 24, 403-416.

Cohen, N. J., \& Eichenbaum, H. (1993). Memory, Amnesia, and the Hippocampal System. Cambridge, MA: MIT Press.

Cohen, N. J., Ryan, J., Hunt, C., Romine, L., Wszalek, T., \& Nash, C. (1999). Hippocampal system and declarative (relational) memory: Summarizing the data from functional neuroimaging studies. Hippocampus, 9(1), 83-98.

Collins, K., \& Mohr, C. (2013). Performance of younger and older adults in lateralized right and left hemisphere asymmetry tasks supports the HAROLD model. Laterality, 18, 491-512.

Craik, F. I. M., \& Byrd, M. (1982). Aging and cognitive deficits: The role of attentional resources. In F. I. M. Craik \& S. E. Trehub (Eds.), Aging and cognitive processes (pp. 191-211). New York, NY: Plenum Press.

Craik, F. I. M. (1982). Selective changes in encoding as a function of reduced processing capacity. In F. Klix, J. Hoffman \& E. van der Meer (Eds.), 
AGING AND ASSOCIATIVE MEMORY

Cognitive research in psychology (pp. 152-161). Berlin, Germany: Deutscher Verlag der Wissenschaffen.

Craik, F. I. M. (1983). On the transfer of information from temporary to permanent memory. Philosophical Transaction of the Royal Society of London, Series B, $302,341-359$.

Craik, F. I. M., \& Byrd, M. (1982). Aging and cognitive deficits: The role of attentional resources. In F. I. M. Craik \& S. E. Trehub (Eds.), Advances in the study of communication and affect: Vol. 8. Aging and cognitive processes (pp. 191-211). New York: Plenum Press.

Craik, F. I. M., Govoni, R., Naveh-Benjamin, M., \& Anderson, N. D. (1996). The effects of divided attention on encoding and retrieval processes in human memory. Journal of Experimental Psychology: General, 125, 159-180.

Craik, F. I. M., \& McDowd, J. M. (1987). Age differences in recall and recognition. Journal of Experimental Psychology: Learning, Memory, and Cognition, 13, 474-479.

Craik, F. I. M., Naveh-Benjamin, M., \& Anderson, N. D. (1998). Encoding and retrieval processes: Similarities and differences. In M. A. Conway, S. E. Gathercole, \& C. Cornoldi (Eds.), Theories of memory II (pp. 61-86). Hillsdale, NJ: Erlbaum.

Craik, F. I. M., \& Rabinowitz, J. C. (1985). The effects of presentation rate and encoding task on age-related memory deficits. Journal of Gerontology, 40, 309315. 
AGING AND ASSOCIATIVE MEMORY

1 Davis, S. W., Kragel, J. E., Madden, D. J., \& Cabeza, R. (2012). The architecture of cross-hemispheric communication in the aging brain: Linking behavior to functional and structural connectivity. Cerebral Cortex, 22(1), 232-242.

de Chastelaine, M., Wang, T. H., Minton, B., Muftuler, L. T., \& Rugg, M. D. (2011). The effects of age, memory performance, and callosal integrity on the neural correlates of successful associative encoding. Cerebral Cortex, 21(9), 21662176.

Daselaar, S., \& Cabeza, R. (2005). Age-Related Changes in Hemispheric Organization. In R. Cabeza, L. Nyberg \& D. C. Park (Eds.), Cognitive Neuroscience of Aging: Linking Cognitive and Cerebral Aging. (pp. 325-353). New York: Oxford University Press.

de Frias, C. M., Dixon, R. A., \& Bäckman, L. (2003). Use of memory compensation strategies is related to pychosocial and health indicators. Journals of Gerontology: Psychological Sciences, 58B, 12-22.

Dew, I. T. Z., \& Giovanello, K. S. (2010). Differential age effects for implicit and explicit conceptual associative memory. Psychology and Aging, 25, 911-921.

Duarte, A., Henson, R. N., \& Graham, K. S. (2008). The effects of aging on the neural correlates of subjective and objective recollection. Cerebral Cortex, 18(9), 2169-80.

Dulas, M. R., \& Duarte, A. (2012). The effects of aging on material-independent and material-dependent neural correlates of source memory retrieval. Cerebral Cortex, 22(1), 37-50. 
AGING AND ASSOCIATIVE MEMORY

1 Dunlosky, J., \& Hertzog, C. (1998). Aging and deficits in associative memory: What is the role of strategy production? Psychology \& Aging, 13, 597-607.

3 Dunlosky, J., \& Hertzog, C. (2001). Measuring strategy production during

4 associative learning: The relative utility of concurrent versus retrospective reports. Memory and Cognition, 29, 247-253.

Dunlosky, J., Kubat-Silman, A., \& Hertzog, C. (2003). Training metacognitive skills improves older adults' associative learning. Psychology and Aging, 18, 340345.

Duverne, S., Motamedinia, S., \& Rugg, M. D. (2009). The Relationship between Aging, Performance, and the Neural Correlates of Successful Memory Encoding. Cerebral Cortex, 19(3), 733-744.

Eichenbaum, H. (2003). Memory systems. In I. B. Weiner (Ed.), Handbook of psychology (pp. 543-559). Hoboken, NJ: Wiley.

Eichenbaum, H., \& Bunsey, M. (1995). On the binding of associations in memory: Clues from studies on the role of the hippocampal region in paired-associate learning. Current Directions in Psychological Science, 4, 19-23.

Erber, J. T. Galt, D. \& Botwinick (1985). Age differences in the effects of contextual framework and word-familiarity on episodic memory. Experimental Aging Research, 11, 101-103

Eyler, L. T., Sherzai, A., Kaup, A. R., \& Jeste, D. V. (2011). A Review of Functional Brain Imaging Correlates of Successful Cognitive Aging Biological Psychiatry, $70(2), 115-122$. 


\section{AGING AND ASSOCIATIVE MEMORY}

1 Freund, A. M., \& Baltes, P. B. (2002). The adaptiveness of selection, optimization,

4 and compensation as strategies of life management: Evidence from a preference study on proverbs. Journals of Gerontology: Psychological Sciences, $57 B, 426-434$.

Glisky, E. L., Rubin, S. R., \& Davidson, P. S. R. (2001). Source memory in older adults: An encoding or retrieval problem? Journal of Experimental Psychology: Learning, Memory, and Cognition, 27, 1131-1146.

Grady, C. L. (2012). Brain ageing: the cognitive neuroscience of ageing. Nature Reviews Neuroscience, 13(7), 492-505.

Grady, C. L., McIntosh, A. R., Horwitz, B., Maisog, J. M., Ungerleider, L. G., Mentis, M. J., . . Haxby, J. V. (1995). Age-related reductions in human recognition memory due to impaired encoding. Science, 269(5221), 218-221.

Healy, M. R., Light, L. L., \& Chung, C. (2005). Dual-process models of associative recognition in young and older adults: Evidence from receiver operating characteristics. Journal of Experimental Psychology: Learning, Memory, and Cognition, 31, 768-788.

Hertzog, C., \& Hultsch, D. F. (2000). Metacognition in adulthood and old age. In F. I. M. Craik (Ed.), The handbook of aging and cognition, (2nd ed., pp. 417-466). Mahwah, NJ: Erlbaum.

Hasher, L., \& Zacks, R. T. (1979). Automatic and effortful processes in memory. Journal of Experimental Psychology: General, 108, 356-388. 
AGING AND ASSOCIATIVE MEMORY

1 Hay, J. F., \& Jacoby, L. L. (1999). Separating habit and recollection in young and

2 older adults: Effects of elaborative processing and distinctiveness. Psychology and Aging, 14, 122-134.

Head, D., \& Isom, M. (2010). Age effects on wayfinding and route learning skills. Behavioral Brain Research, 209, 49-58.

Henke, K., Buck, A., Weber, B., \& Wieser, H. G. (1997). Human hippocampus establishes associations in memory. Hippocampus, 7, 249-256.

Hertzog, C., Dunlosky, J., Robinson, A. E. (2009). Intellectual abilities and metacognitive beliefs influence spontaneous use of effective encoding strategies. Unpublished manuscript.

Hertzog, C., Price, J., and Dunlosky, J. (2012). Age Differences in the Effects of Experimenter-Instructed Versus Self-Generated Strategy Use. Experimental Aging Research, 38, 42-62.

Hockley,W. E., \& Consoli, A. (1999). Familiarity and recollection in item and associative recognition. Memory and Cognition, 27, 657-664.

Hoyer, W. J., \& Verhaeghen, P. (2006). Memory aging. In J. E. Birren \& K. W. Schaie (Eds.), Handbook of the psychology of aging (pp. 209-232). Amsterdam, Netherlands: Elsevier.

Huang, C.-M., Polk, T. A., Goh, J. O., \& Park, D. C. (2012). Both left and right posterior parietal activations contribute to compensatory processes in normal aging. Neuropsychologia, 50(1), 55-66. 


\section{AGING AND ASSOCIATIVE MEMORY}

1 Jacoby, L. L., \& Dallas, M. (1981). On the relationship between autobiographical memory and perceptual learning. Journal of Experimental Psychology: General, 110, 306-340.

4 Jacoby, L. L., Toth, J. P.. \& Yonelinas, A. P. (1993). Separating conscious and unconscious influences of memory: Attention, awareness, and control. Journal of Experimental Psychology: General, 122, 739-154.

James, L. E., Fogler, K. A., \& Tauber, S. K. (2008). Recognition memory measures yield disproportionate effects of aging on learning face-name associations. Psychology and Aging, 23, 657-664.

Jennings, J. M., \& Jacoby, L. L. (1993). Automatic versus intentional uses of memory: Aging, attention, and control. Psychology and Aging, 8, 283-293.

Kausler, D. (1994). Learning and memory in normal aging. San Diego, CA: Academic Press.

Kersten, A. W., Earles, J. L., Curtayne, E. S., \& Lane, J. C. (2008). Adult age differences in binding actors and actions in memory for events. Memory \& Cognition, 36, 119-131.

Kessels, R. P. C., van Doormaal, A., \& Janzen, G. (2011). Landmark recognition in Alzheimer's: Spare implicit memory for objects relevant for navigation. PLoS One, 6(4), e18611. doi:10.1371/journal.pone.0018611.t001

Kilb, A., \& Naveh-Benjamin, M. (2007). Paying attention to binding: Is the associative deficit of older adults mediated by reduced attentional resources? Memory \& Cognition, 35, 1162-1174. 
AGING AND ASSOCIATIVE MEMORY

1 Koutstaal, W. (2003). Older adults encode-but do not always use-perceptual details: Intentional versus unintentional effects of detail on memory judgments. Psychological Science, 14, 189-193.

4 Koutstaal, W. (2006). Flexible remembering. Psychonomic Bulletin \& Review, 13,

5 84-91.

Kroll, N. E. A., Knight, R., Metcalfe, J., Wolf, E. S., \& Tulving, E. (1996). Cohesion failure as a source of memory illusions. Journal of Memory \& Language, 35, 176-196.

Lachman, M. E. (2006). Perceived control over aging-related declines: Adaptive beliefs and behaviors. Current Directions in Psychological Science, 15(6), 282286.

Lachman, M. E. \& Agrigoroaei, S. (2012). Low perceived control as a risk factor for episodic memory: The mediational role of anxiety and task interference. Memory and Cognition, 40, 287-296.

Lachman, M.E., \& Andreoletti, C. (2006). Strategy use mediates the relationship between control beliefs and memory performance for middle-aged and older adults. Journals of Gerontology: Psychological Sciences, 61B, 88-94.

Li, S.-C., Naveh-Benjamin, M., \& Lindenberger, U. (2005). Aging neuromodulation impairs associative binding. Psychological Science, 16, 445-450.

Light, L. L. (1991). Memory and aging: Four hypotheses in search of data. Annual Review of Psychology, 43, 333-376. 


\section{AGING AND ASSOCIATIVE MEMORY}

Light, L. L., Patterson, M. M., Chung, C., \& Healy, M. R. (2004). Effects of repetition and response deadline on associative recognition in young and older adults. Memory \& Cognition, 32, 1182-1193.

Light, L. L., \& Prull, M. W. (1995). Aging, divided attention, and repetition priming. Swiss Journal of Psychology, 54, 87-101.

Macht, M. L., \& Buschke, H. (1983). Age differences in cognitive effort in recall. Journal of Gerontology, 28, 695-700.

Mandler, G. (1980). Recognizing: The judgment of previous occurrence. Psychological Review, 87, 252-271.

Maylor, E. A. (1995). Remembering versus knowing television theme tunes in middle-aged and elderly adults. British Journal of Psychology, 86, 21-25.

McDougall, G. J., \& Kang, J. (2003). Memory self-efficacy and memory performance in older males. International Journal of Men's Health, 2, 131-147.

McGillivray, S., \& Castel, A. D. (2010). Memory for age-face associations in younger and older adults: The role of generation and schematic support. Psychology and Aging, 25, 822-832.

Mitchell, K. J., Johnson, M. K., Raye, C. L., \& D’Esposito, M. (2000a). fMRI evidence of age-related hippocampal dysfunction in feature binding in working memory. Cognitive Brain Research, 10, 197-206.

Mitchell, K. J., Johnson, M. K., Raye, C. L., Mather, M., \& D’Esposito, M. (2000b). Aging and reflective processes of working memory: Binding and test load deficits. Psychology and Aging, 15, 527-541. 
AGING AND ASSOCIATIVE MEMORY

Morcom, A. M., \& Friston, K. J. (2012). Decoding episodic memory in ageing: A Bayesian analysis of activity patterns predicting memory. NeuroImage, 59(2), $1772-1782$.

Moscovitch, M. (1994). Cognitive resources and dual-task interference effects at retrieval in normal people: The role of the frontal lobes and medial temporal cortex. Neuropsychology, 8, 524-534.

Moscovitch, M., \& Winocur, G. (1992). The neuropsychology of memory and aging. In F. I. M. Craik \& T. A. Salthouse (Eds.), The handbook of aging and cognition (pp. 315-372). Hillsdale, NJ: Erlbaum.

Naveh-Benjamin, M. (2000). Adult age differences in memory performance: Tests of an associative deficit hypothesis. Journal of Experimental Psychology: Learning, Memory, and Cognition, 26, 1170-1187.

Naveh-Benjamin, M., Brav, T. K., \& Levy, O. (2007). The associative memory deficit of older adults: The role of strategy utilization. Psychology and Aging, 22, 202208.

Naveh-Benjamin, M., \& Craik, F. I. M. (1995). Memory for context and its use in item memory: Comparisons of younger and older persons. Psychology and Aging, 10, 284-293.

Naveh-Benjamin, M., Craik, F. I. M., Guez, J., \& Krueger, S. (2005). Divided attention in younger and older adults: Effects of strategy and relatedness on memory performance and secondary task costs. Journal of Experimental Psychology: Learning, Memory, \& Cognition, 31, 520-537. 


\section{AGING AND ASSOCIATIVE MEMORY}

Naveh-Benjamin, M., Guez, J., Kilb, A., \& Reedy, S. (2004). The associative memory deficit of older adults: Further support using face-name associations. Psychology and Aging, 19, 541-546.

Naveh-Benjamin, M., Hussain, Z., Guez, J., \& Bar-On, M. (2003). Adult age differences in episodic memory: Further support for an associative deficit hypothesis. Journal of Experimental Psychology: Learning, Memory, and Cognition, 29, 826-837.

Naveh-Benjamin, M., \& Old, S. (2008). Aging and memory (humans). In J. H. Byrne, H. Eichenbaum, R. Menzel, H. L. Roedige, \& D. Sweatt (Eds.), Learning and memory: A comprehensive reference (pp. 787-808). Oxford, UK: Elsevier.

Naveh-Benjamin, M., Shing, Y.-L., Kilb, A., Werkle-Bergner, M., Lindenberger, U., \& Li, S.-C. (2009). Adult age differences in memory for name-face associations: The effects of intentional and incidental learning. Memory, 17, 220-232.

Nyberg, L., Nilsson, L.-G., Olofsson, U., \& Bäckman, L. (1997). Effects of division of attention during encoding and retrieval on age differences in episodic memory. Experimental Aging Research, 23, 137-143.

Old, S., \& Naveh-Benjamin, M. (2008). Memory for people and their actions: Further evidence for an age-related associative deficit. Psychology and Aging, $23,467-472$.

Park, D. C., Polk, T. A., Mikels, J. A., Taylor, S. F., \& Marshuetz, C. (2001). Cerebral aging: Integration of brain and behavioral models of cognitive function. Dialogues in Clinical Neuroscience, 3(3), 16. 
AGING AND ASSOCIATIVE MEMORY

1 Park, D. C., \& Reuter-Lorenz, P. (2009). The adaptive Brain: Aging and neurocognitive scaffolding. Annual Review of Psychology, 60, 173-196.

3 Park, D. C., Puglisi, J. T., \& Smith, A. D. (1986). Memory for pictures: Does an agerelated decline exist? Psychology and Aging, 1, 11-17.

5

Park, D. C., Smith, A. D., Dudley, W. N., \& Lafronza, V. N. (1989). Effects of age and a divided attention task presented during encoding and retrieval on memory. Journal of Experimental Psychology: Learning, Memory, and Cognition, 15, 1185-1191.

Patterson, M. M., \& Hertzog, C. (2010). The effects of age in four alternative forcedchoice item and associative recognition tasks. Psychology and Aging, 25, 235238.

Persson, J., Nyberg, L., Lind, J., Larsson, A., Nilsson, L. G., Ingvar, M., \& Buckner, R. L. (2006). Structure-function correlates of cognitive decline in aging. Cerebral Cortex, 16(7), 907-915.

Posner, M. I., \& Snyder, C. R. R. (1975). Attention and cognitive control. In R. L., Solso. Information processing and cognition. The Loyola symposium. Hillsdale, NJ: Lawrence. Erlbaum Associates.

Pudas, S. Y., Persson, J., Josefsson, M., de Luna, X., Nilsson, L.-G., \& Nyberg, L. (2013). BrainCharacteristics of Individuals Resisting Age-Related Cognitive Decline over Two Decades. Journal of Neuroscience, 33(20), 8668-8677. 
AGING AND ASSOCIATIVE MEMORY

1 Rajah, M. N., \& D'Esposito, M. (2005). Region-specific changes in prefrontal function with age: A review of PET and fMRI studies on working and episodic memory. Brain, 128(9), 1964-1983.

Rebok, G. W., \& Balcerak, L. J. (1989). Memory self-efficacy and performance differences in young and old adults: The effect of mnemonic training. Developmental Psychology, 25, 714-721.

Rendell, P. G., Castel, A. D., \& Craik, F. I. M. (2005). Memory for proper names in old age: A disproportionate impairment? Quarterly Journal of Experimental Psychology Section A, 58, 54-71.

Reuter-Lorenz, P. (2002). New visions of the aging mind and brain. Trends in Cognitive Sciences, 6(9), 394-400.

Rhodes, M. G., Castel, A. D., \& Jacoby, L. L. (2008). Associative recognition of face pairs by younger and older adults: The role of familiarity-based processing. Psychology and Aging, 23, 239-249

Rosen, A. C., Prull, M. W., O'Hara, R., Race, E. A., Desmond, J. E., Glover, G. H., Yesavage, J. A., \& Gabrieli, J. D. E. (2002). Variable effects of aging on frontal lobe contributions to memory. NeuroReport, 13(18), 2425-2428.

Salthouse, T. A. (1996). The processing-speed theory of adult age differences in cognition. Psychological Review. 103, 403-428.

Salthouse, T. A. (2004). What and When of Cognitive Aging. Current Directions in Psychological Science, 13, 140-144. 
AGING AND ASSOCIATIVE MEMORY

1

2

3

4

Salthouse, T. A., Rogan, J. D., \& Prill, K. A. (1984). Division of attention: Age differences on a visually presented memory task. Memory \& Cognition, 23, 5971.

Schneider, W., \& Shiffrin, R. M. (1977). Controlled and automatic human information processing: I. Detection, search, and attention. Psychological Review, 84, 1-66.

Smith, A. D., Park, D. C., Earles, J. L., Shaw, R. J., \& Whiting, W. L. (1998). Age differences in context integration in memory. Psychology and Aging, 13, 21-28.

Spaniol, J., Madden, D. J., \& Voss, A. (2006). A diffusion model analysis of adult age differences in episodic and semantic long-term memory retrieval. Journal of Experimental Psychology: Learning, Memory, and Cognition, 32, 101-107.

Steffener, J., \& Stern, Y. (2012). Exploring the neural basis of cognitive reserve in aging. Biochmica et Biophysica Acta (BBA)-Molecular Basis of Disease, 1822, $467-473$.

Stern, Y., Habeck, C., Moeller, J., Scarmeas, N., Anderson, K. E., Hilton, H. J., Flynn, J., Sackeim, H., \& van Heertum, R. (2005). Brain networks associated with cognitive reserve in healthy young and old adults. Cerebral Cortex, 15(4), 394-402.

Titov, N, \& Knight, R. G. (1997). Adult age differences in controlled and automatic memory processing. Psychology and Aging, 12, 565-573.

Tulving, E. (1985). Memory and consciousness. Canadian Journal of Psychology, 26, $1-12$. 
AGING AND ASSOCIATIVE MEMORY

1 Wallenstein, G. V., Eichenbaum, H., \& Hasselmo, M. E. (1998). The hippocampus as an associator of discontiguous events. Trends in Neurosciences, 21, 317-323.

3 Whiting, W. L., \& Smith, A. D. (1997). Differential age-related processing

4

5

6

16 17 limitations in recall and recognition tasks. Psychology and Aging, 12, 216-224.

Yonelinas, A. P. (1997). Recognition memory ROCs for item and associative information: The contribution of recollection and familiarity. Memory \& Cognition, 25, 747-763.

Yonelinas, A. P. (2002). The nature of recollection and familiarity: A review of 30 years of research. Journal of Memory and Language, 46, 441-517

Zacks, R. T., Hasher, L., \& Li, K. Z. H. (2000). Human memory. In T. A. Salthouse \& F. I. M. Craik (Eds.), Handbook of aging and cognition, (2nd ed., pp. 293-357). Mahwah, NJ: Erlbaum.

Zarahn, E., Rakitin, B., Abela, D., Flynn, J., \& Stern, Y. (2007). Age-related changes in brain activation during a delayed item recognition task. Neurobiology of Aging, 28(5), 784-798. 


\section{Appendix: Supplementary Figures}
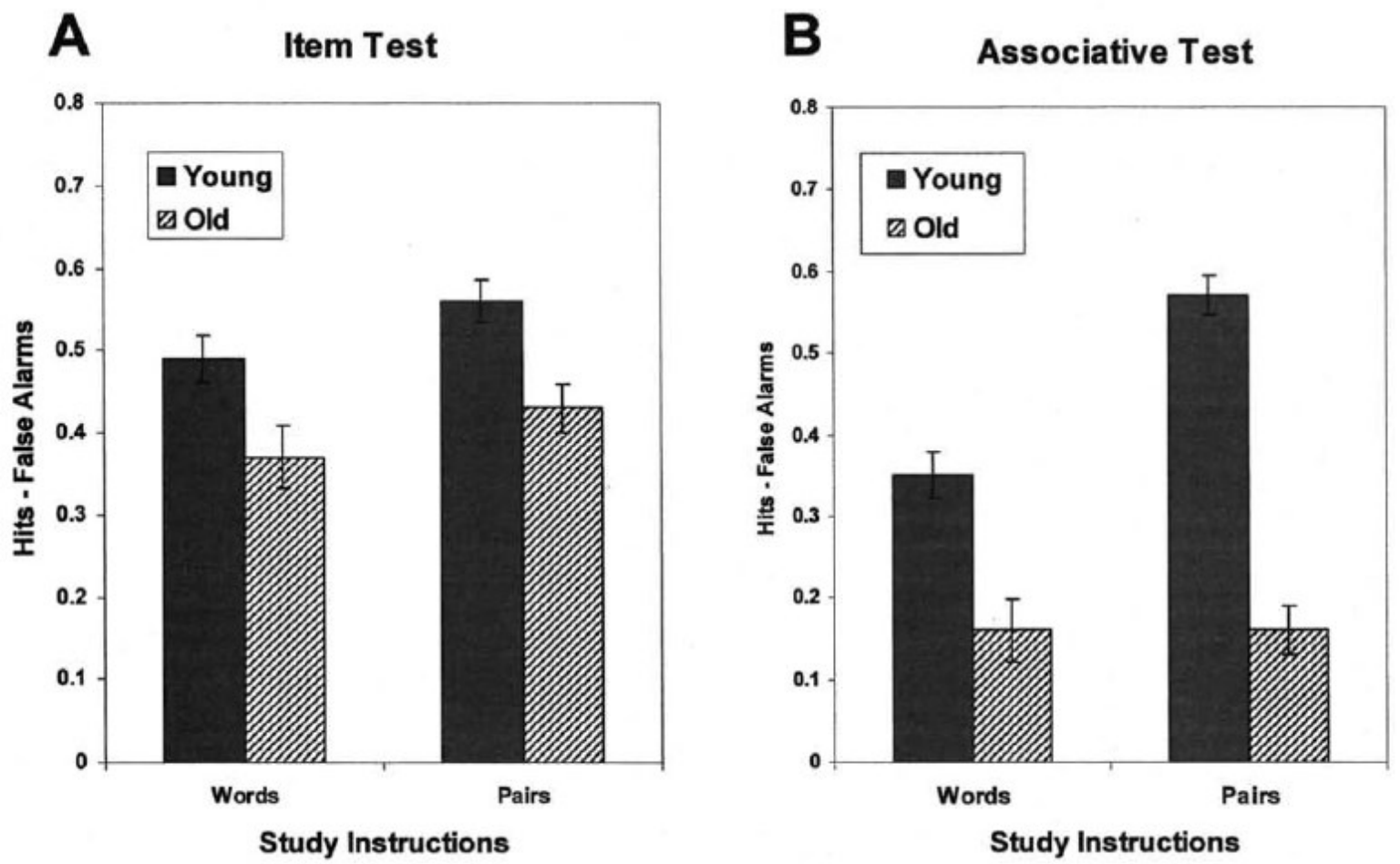

Figure 1.1. Proportion of hits minus proportion of false for different age groups in the item and associative recognition tests under the different study conditions. 'Hits' refer to correct recognition of old items whereas 'false alarms' refer to the incorrect recognition of distractors/lures. Bars represent $\pm 1 \mathrm{SE}$. Source: Naveh-Benjamin, M., 2000, Journal of Experimental Psychology: Learning, Memory, \& Cognition, 26, 1170-1187. Reproduced with permission. 


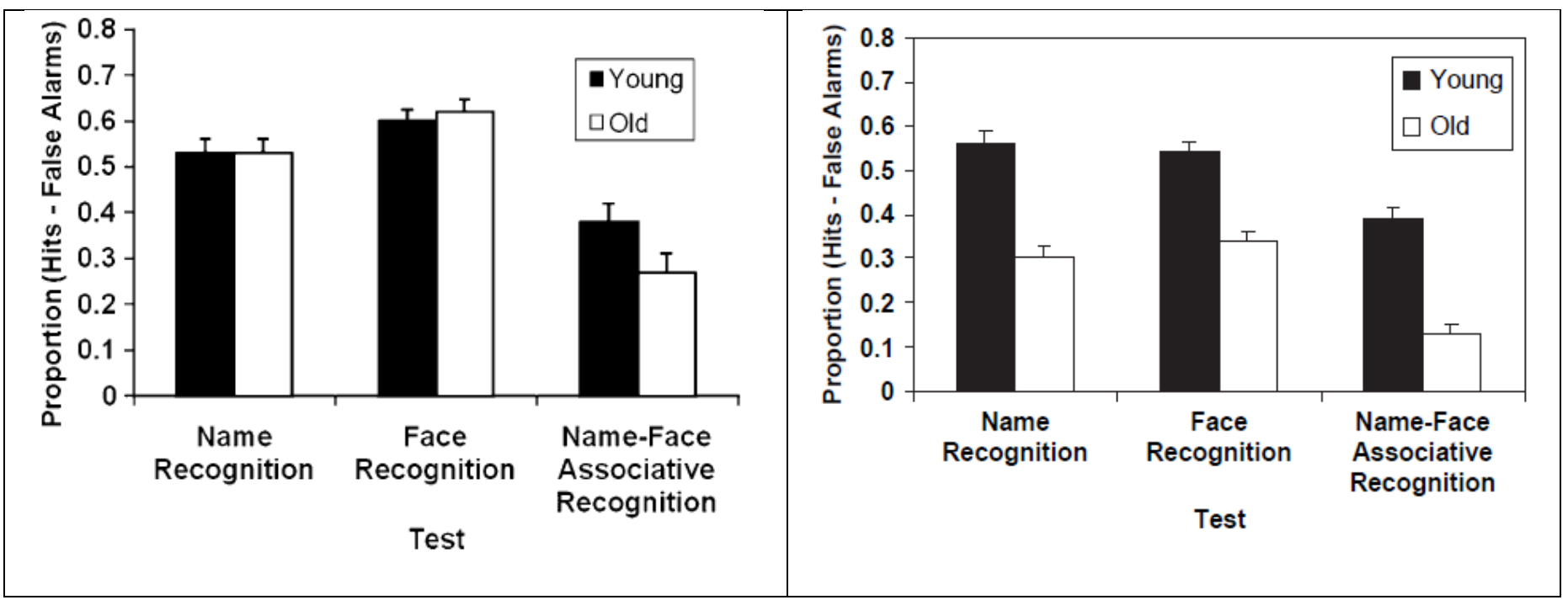

Figure 1.2. Proportion of hits minus proportion of false for different age groups in the item and associative recognition tests under intentional (left) and incidental learning instructions (right). Bars represent \pm 1 SE. Source: Naveh-Benjamin, M., Shing, Y.-L., Kilb, A., Werkle-Bergner, M., Lindenberger, U., \& Li, S.-C. (2009). Adult age differences in memory for name-face associations: The effects of intentional and incidental learning. Memory, 17, 220-232). Reproduced with permission.

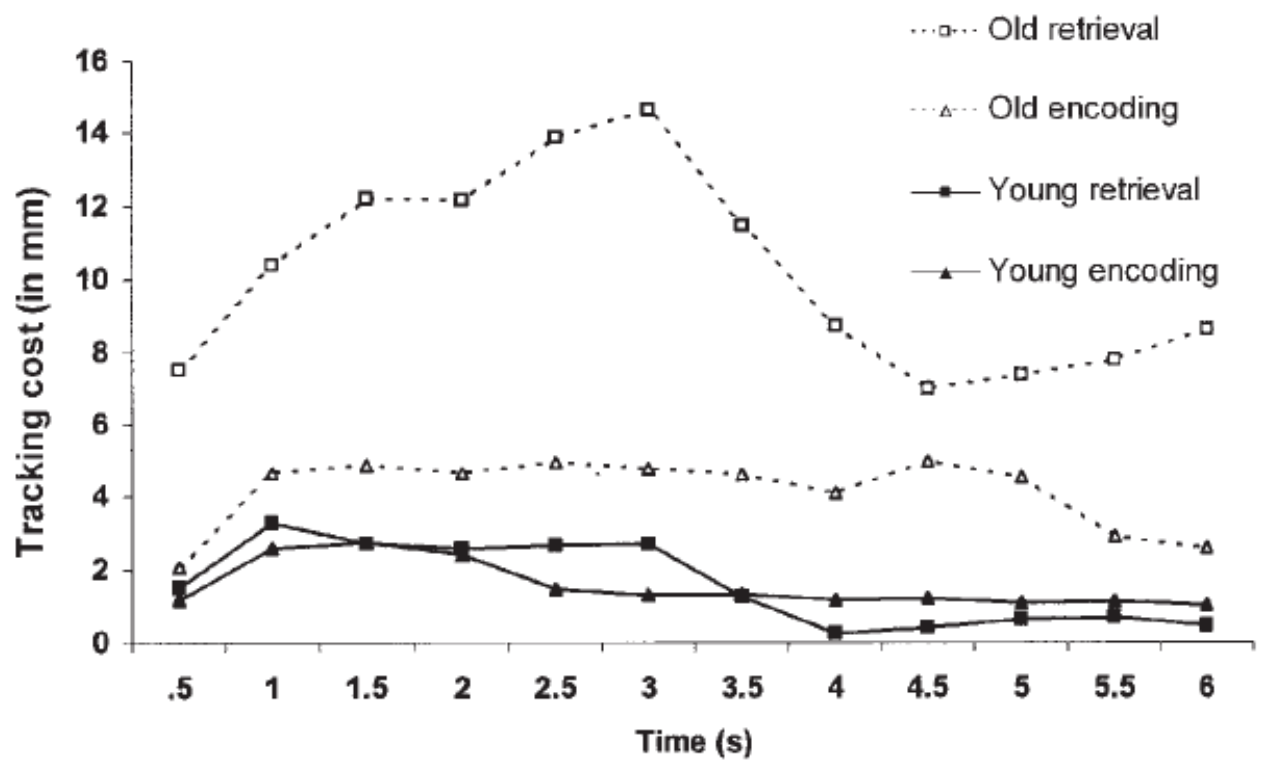

Figure 1.3. Temporal distribution of secondary tracking costs for younger and older adults averaged across the 6seconds encoding and retrieval periods. Tracking costs represented attentional costs and were computed by subtracting the performance measure--the difference in distance between the white dot (controlled by participants) and a green asterisk (moving on the screen) — of the dual-task (divided attention) condition from the single-task (full attention) condition. Source: Naveh-Benjamin, M., Craik, F. I. M., Guez, J., \& Krueger, S. (2005). Divided attention in younger and older adults: Effects of strategy and relatedness on memory performance and secondary task costs. Journal of Experimental Psychology: Learning, Memory, \& Cognition, 31, 520-537. Reproduced with permission. 


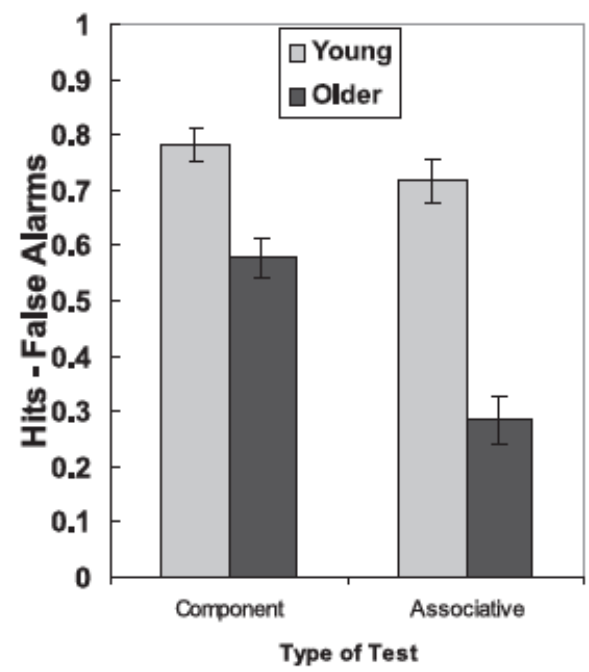

Intentional Learning

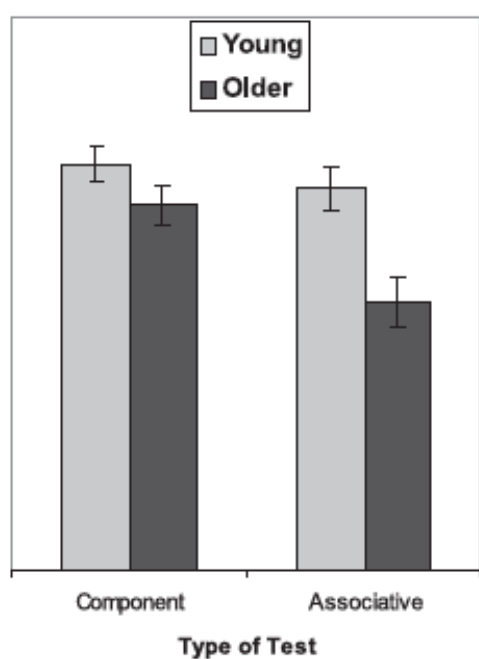

Associative Strategy at Encoding

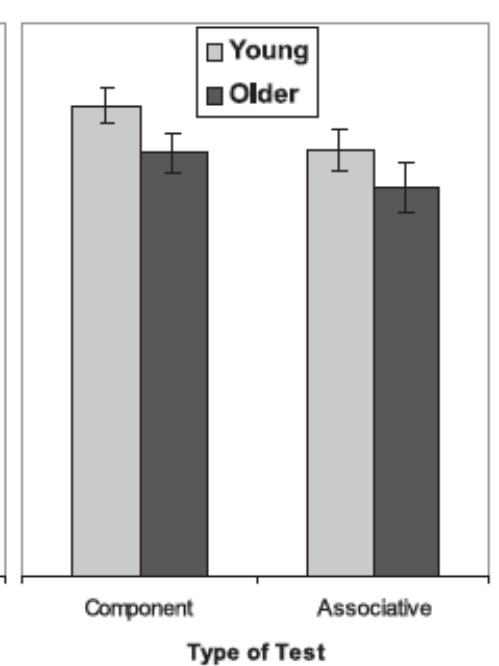

Associative Strategy at Encoding and Retrieval

Figure 1.4. Proportion of hits minus proportion of false alarms for different age groups in the item and associative recognition tests in three conditions of intentional instructions with two involving strategy use. Bars represent $\pm 1 \mathrm{SE}$. Source: Naveh-Benjamin, M., Brav, T. K., \& Levy, O. (2007). The associative memory deficit of older adults: The role of strategy utilization. Psychology and Aging, 22, 202-208. Reproduced with permission. 